\title{
DETERMINANTS OF ADVANCED BOOKING
}

\author{
Juan L. Nicolau \\ Dpt. of Marketing \\ Faculty of Economics \\ University of Alicante, Spain \\ e-mail: jl.nicolau@ua.es \\ Lorenzo Masiero (*) \\ School of Hotel and Tourism Management \\ The Hong Kong Polytechnic University \\ 17 Science Museum Road \\ TST East, Kowloon, Hong Kong \\ Tel: +852 3400 2179; Fax: +852 23629362 \\ e-mail: lorenzo.masiero@polyu.edu.hk
}




\section{DETERMINANTS OF ADVANCED BOOKING}

Keywords: advanced booking; reservation; prices; accommodation; distribution channels.

Individuals know that the optimal time to make hotel reservations is critical because of the close relationship between advanced booking and travel expenditures (Thrane, 2016). This task is even more complex because the expectations of advanced-booking travellers change over time (Chen and Schwartz, 2008). Hence, their expectations of finding a good price vary and depend on the proximity of the travellers to the date of stay. In an attempt to clarify this issue, the objective of this study is to obtain the determinants of the time that people book a hotel in advance.

Accommodation is a major component of tourist expenditures. The anticipation with which bookings are made remains a critical issue that determines the level of such expenditures. Chen and Schwartz (2008) emphasized that uncertainty leads tourism managers to be considerably vigilant on the time tourists make their reservations. The advent of online booking activities has resulted in many purchase decisions becoming time dependent (Lynch and Zauberman 2006). Nonetheless, if intangibility is considered, the fact that one does not know what will receive after buying a product makes the booking time a relevant decision. Tourists want to ensure that everything will go according to plan; however, they also seek for "good prices." The Internet has reduced information asymmetries between guests and accommodation firms, and has made clients follow deal-seeking behaviour (Chen and Schwartz, 2008). Therefore, the optimal time for advanced booking is a crucial point for guests and firms. To date, this situation is considerably prevalent and some websites show the future evolution of prices rather than merely allowing individuals to determine prices and room availability. This feature enables customers to render good and informed decisions on the date of their booking. Even the timing decision could be conditioned by the distribution channels that individuals use for information search (Pearce and Schott, 2005).

The expanded theoretical model of Schwartz (2008) states that the traditional advancedbooking decision model must be considered dynamic rather than merely static over time. In this context, it is suggested that the time before the day of consumption serves as a cue in booking decisions. People know that booking considerably in advance or at the last minute enables them to obtain good deals (Chen and Schwartz, 2008). In between, many 
different factors can affect booking decisions. In fact, these authors claim that it is not easy to identify the factors that explain the fluctuations between 30 and 2 days before the date of stay. Accordingly, this observation opens a future avenue for research.

Consequently, the objective of the current investigation is to explore potential factors that could explain decisions on advanced booking. This study focuses on major travel determinant factors, such as prices, travel party size, accommodation type (i.e., hotels vs. holiday homes), length of stay, booking month, and distribution channel. As specific empirical applications on advanced booking are not common, this article tries to add to the literature in an attempt to contribute to the aforementioned research thread.

\section{RESEARCH DESIGN}

The empirical application is based on a set of bookings for accommodations obtained in Ascona-Locarno, Ticino, Switzerland. Different sales channels are represented in the database; thus, we could test the different effects of each channel. In particular, the local destination marketing organization (DMO) has two booking platforms, namely, online (i.e., through its website) and offline (i.e., through its call center). In addition, the local DMO provides accommodation owners the possibility of using an ad hoc channel manager in dealing with the bookings from different channels, including online travel agents (OTAs), their own websites, and the two DMO channels. A total of 2,728 bookings were successfully recorded. Focusing on the variable of interest, the data show strong heterogeneity in the variable "days of advanced booking," with a median of 15 days prior to the time of stay and a distribution ranging from bookings made on the same day of the stay to those made 321 days before the actual stay. This heterogeneity is appropriate for the objective of this study, that is, to determine the factors that explain the variability. The sample descriptive statistics for the other variables used in the analysis are reported in Table 1.

\section{TABLE 1 ABOUT HERE}

To analyze count data such as the days of advanced booking, a count model is proposed. The negative binomial distribution represents a typical probability distribution for count data and leads to the estimation of the so called NegBin model. Accordingly, an individual $t$ will select a number $y_{t}$ of days with the following probability: 


$$
P\left(y_{t}\right)=\frac{\Gamma\left(\alpha^{-1}+y_{t}\right)}{\Gamma\left(\alpha^{-1}\right) \Gamma\left(y_{t}+1\right)}\left(\frac{\alpha^{-1}}{\alpha^{-1}+e^{\sum_{k=1}^{K} \beta_{k} x_{t k}}}\right)^{\alpha^{-1}}\left(\frac{e^{\sum_{k=1}^{K} \beta_{k} x_{t k}}}{\alpha^{-1}+e^{\sum_{k=1}^{K} \beta_{k} x_{t k}}}\right)^{y_{t}} \forall y_{t}=\{0,1,2, \ldots\},
$$

where $\Gamma$ represents the Gamma function, $x_{t k}$ is the characteristic $k$ of individual $t$, and $\beta_{\mathrm{k}}$ is the parameter that indicates the effect of $x_{t k}$ on $P\left(y_{t}\right)$. The parameter $\alpha$ covers the dispersion of the observations, such that $E\left(y_{t}\right)=e^{\sum_{k=1}^{K} \beta_{k} x_{t k}}=\lambda_{t}$ and $V\left(y_{t}\right)=e^{\sum_{k=1}^{K} \beta_{k} x_{t k}}+\alpha \cdot e^{2 \sum_{k=1}^{K} \beta_{k} x_{t k}}=\lambda_{t}+\alpha \cdot \lambda_{t}^{2}$. Note that the Poisson distribution is a special case of the negative binomial distribution where mean $E\left(y_{t}\right)$ and variance $V\left(y_{t}\right)$ are the same. Therefore, by testing $\alpha=0$, we could determine if the NegBin model is better than the Poisson model (Gurmu and Trivedi, 1996) ${ }^{1}$.

\section{RESULTS}

Table 2 presents the results of the NegBin model in terms of the significance of the parameters and marginal effects. Three equations are estimated to control for collinearity. The overall performance of the models is tested through the Likelihood ratio test (LR statistic) which confirms that the three estimated model fit the data better than a model with only the constant term. The comparison among estimated models relies on the Akaike information criterion (Akaike IC). Models with low Akaike IC values are preferred. Equation 1 shows the effect of prices per night per person on the days of advanced booking. Prices exert a curvilinear effect with a significant and negative parameter for the linear variable and a significant and positive parameter for the quadratic term. Graph 1 shows that the entire effect is decreasing. However, this decrement is less than proportional and reaches a point where any additional increment in prices has no major effect on the days of advanced booking.

\section{TABLE 2 ABOUT HERE}

\footnotetext{
${ }^{1}$ The discrete character of the dependent variable (number of days) favors the use of count data models. The regression analysis would present bias problems and the Multinomial Logit Model would suffer from inefficiency problems derived from the potentially enormous number of alternatives (the model should use as many alternatives as the different "number of days" the individuals in the sample have booked in advance).
} 


\section{GRAPH 1 ABOUT HERE}

Equation 2 presents the effects of accommodation type, length of stay, and the month when the booking was made. In particular, we determine that holiday homes lead to $30.5 \%$ more days of advanced booking than hotels. The lower number of holiday homes than hotel rooms may lead people to book considerably in advance to avoid the risk of non-availability. Note that holiday homes are popular at the destination that this study analysed; however, the number of hotels is still substantial. Regarding length of stay, each additional night implies an increase of $13.7 \%$ days of anticipation. This increase means that the longer the stay, the safer the individuals play because they want to guarantee they will find and retain the accommodation for the expected entire length of stay. For the booking month, July shows $4.7 \%$ more days in advance than August (i.e., the reference base, to which comparisons are made), but the rest of the months present fewer days than August. In particular, January has $46.21 \%$ as many days as August; February, 60.19\%; March, 76.31\%; April, 86.59\%; May, 94.37\%; June, 97.01\%; September, 94.41\%; October, 92.30\%; November, 87.02\%; and December, 91.66\%. The popularity of the destination's summer activities leads people to book considerably in advance during this period than any other month of the year.

Equation 3 presents the effect of party size and sales channel. For party size, each additional member has an effect of $8.3 \%$ increase on the days of advanced reservation. Having more people in the group implies more constraints to book the adequate number of rooms; thus, they tend to anticipate the reservation. For sales channels, "OTAs hotel" shows no significant difference compared with "Own website hotel" (i.e., the reference base for the accommodation type "hotel"). "DMO website hotel" and "DMO call center hotel" have $7.06 \%$ and $61.8 \%$ more days, respectively, than "Own website hotel." Relative to "Own website Holiday home" (i.e., the reference base for the accommodation type "holiday home"), “OTAs Holiday home," "DMO website Holiday home," and "DMO call center Holiday home" present 131.2\%, 74.8\%, and 109.9\% more days, respectively, than "OTAs Holiday home."

\section{CONCLUSIONS}

With the advent of Internet reservation, advanced booking has become a prevalent strategy. Given the lack of a larger empirical evidence of explanatory factors of advanced booking, this study proposes the analysis of a set of bookings for hotels and holiday homes 
that were made via four different sales channels (i.e., online and offline). These channels are own website, OTAs, DMO website, and DMO call center. Accordingly, major travel determinant factors, such as prices, travel party size, accommodation type, length of stay, month, and distribution channel, are assumed to affect the days of advanced booking. The results obtained confirm that the proposed variables are explanatory factors of the variable of interest, that is, the days of advanced booking. In particular, prices have a decreasing effect that is less than proportional. Increasing prices from 100 to 200 has a larger reduction in the days of advanced booking than increasing prices from 1100 to 1200 . The accommodation type "Holiday homes" and numerous nights result in a positive effect on the anticipation of reservations. Booking in July and August, as well as large party size, imply longer anticipation. For sales channels, the platforms managed by DMO are related with additional days of advanced booking, in both accommodation types: hotels and holiday homes. However, the use of OTAs results in an increment of anticipation only for holiday homes (not for hotels). In general, these results show that it is possible to identify the factors that lead an individual to book with a number of anticipated days. While the claim stated at the beginning that managers must be vigilant to this issue is strongly maintained, the results of this empirical application provides insights into price fluctuations before the date of stay. More importantly, the fact that some of these explanatory factors are tied to individual characteristics (e.g. party size) and trip characteristics (e.g. length of stay), segmentation strategies can be developed according to these criteria and revenue management tactics can be implemented on the basis of these features.

From a statistical perspective, Equation 2 represents the best specification among the three estimated models as it obtained the lowest Akaike IC. This finding indicates that accommodation type, length of stay and month of the year are the variables that mostly contribute to the explanation of the pattern observed in the days of advanced booking. In terms of managerial implications, the prevalent online booking strategy makes the results reached for the different distribution channels particularly relevant. First, a distinct pattern is determined depending on the accommodation type. Second, the same type of channel exerts a different effect on each type of accommodation (e.g., while using OTAs has an $131.2 \%$ increment for holiday homes, but there is no effect on hotels compared with their respective reference bases). Third, sales channels linked to publicly owned tourism entities, such as DMO, result in an increase of days of advanced booking in all cases, hotels, and holiday homes. Close collaboration with public tourism-related entities 
may facilitate the accomplishment of the goals of accommodation companies because the latter often prefers having anticipated bookings for considerably price-sensitive guests, thereby assuring the projected profitability.

This study is an initial step in analyzing the determinants of advanced booking. With the rapid evolution of booking alternatives, new factors, particularly those related to the plethora of alternative sales channels, should be investigated.

\section{REFERENCES}

Chih-Chen, C. and Schwartz, Z. (2008). “Timing Matters: Travelers' Advanced-Booking Expectations and Decisions", Journal of Travel Research, 47, 35-42.

Gurmu, S. and Trivedi, P. K. (1996). "Excess Zeros in Count Models for Recreational Trips”, Journal of Business \& Economic Statistics, 14(4), 469-477.

Lynch, J. G. and G. Zauberman (2006). "When Do You Want It? Time, Decisions, and Public Policy”, Journal of Public Policy and Marketing, 25 (1): 67-78.

Pearce, D. G. and C. Schott (2005). "Tourism Distribution Channels: The Visitors' Perspective", Journal of Travel Research, 44: 50-63.

Schwartz, Z. (2008). "Time, Price and Advanced Booking of Hotel Rooms", International Journal of Hospitality and Tourism Administration, 9, 2, 128-146.

Thrane, C. (2016) “The determinants of Norwegians' summer tourism expenditure: foreign and domestic trips", Tourism Economics, 22, 1, 31-46. 


\begin{tabular}{|c|c|c|c|c|}
\hline & Mean (or \%) & St. dev. & Min & Max \\
\hline Advance booking (days) & 38.38 & 51.30 & 0 & 321 \\
\hline Price per night (CHF) & 207.19 & 85.10 & 50 & 495 \\
\hline Length of stay (nights) & 2.85 & 2.47 & 1 & 14 \\
\hline Travel party size (people) & 2.14 & 0.88 & 1 & 9 \\
\hline Price per person per night (CHF) & 103.99 & 42.99 & 16 & 336 \\
\hline \multicolumn{5}{|l|}{ Type of accommodation (100\%) } \\
\hline Hotels & $80.94 \%$ & & & \\
\hline Holiday homes & $19.06 \%$ & & & \\
\hline \multicolumn{5}{|l|}{ Hotel sales channels (100\%) } \\
\hline OTAs & $58.29 \%$ & & & \\
\hline Own website & $8.38 \%$ & & & \\
\hline DMO website & $27.13 \%$ & & & \\
\hline DMO call center & $6.20 \%$ & & & \\
\hline \multicolumn{5}{|l|}{ Holiday home sales channels (100\%) } \\
\hline OTAs & $18.08 \%$ & & & \\
\hline Own website & $0.58 \%$ & & & \\
\hline DMO website & $45.58 \%$ & & & \\
\hline DMO call center & $35.77 \%$ & & & \\
\hline \multicolumn{5}{|l|}{ Months (100\%) } \\
\hline January & $3.85 \%$ & & & \\
\hline February & $3.52 \%$ & & & \\
\hline March & $10.48 \%$ & & & \\
\hline April & $9.64 \%$ & & & \\
\hline May & $11.66 \%$ & & & \\
\hline June & $12.54 \%$ & & & \\
\hline July & $16.39 \%$ & & & \\
\hline August & $8.94 \%$ & & & \\
\hline September & $9.49 \%$ & & & \\
\hline October & $7.70 \%$ & & & \\
\hline November & $2.24 \%$ & & & \\
\hline December & $3.56 \%$ & & & \\
\hline
\end{tabular}


Table 2. Determinants of reservation anticipation

\begin{tabular}{|c|c|c|c|c|c|c|}
\hline Variables & Equation 1 & $\begin{array}{c}\text { Marginal } \\
\text { effect }\end{array}$ & Equation 2 & $\begin{array}{c}\text { Marginal } \\
\text { effect }\end{array}$ & Equation 3 & $\begin{array}{c}\text { Marginal } \\
\text { effect }\end{array}$ \\
\hline Price per night & $\begin{array}{l}-0.0057^{\mathrm{a}} \\
(0.0014)\end{array}$ & 0.9943 & & & & \\
\hline Price per night ${ }^{\wedge} 2$ & $\begin{array}{c}0.00001^{\mathrm{a}} \\
(0.000002)\end{array}$ & 1.00000935 & & & & \\
\hline $\begin{array}{l}\text { Accommodation } \\
\text { type }\end{array}$ & & & $\begin{array}{l}0.2666^{\mathrm{a}} \\
(0.0912)\end{array}$ & 1.3056 & & \\
\hline Nights & & & $\begin{array}{l}0.1285^{a} \\
(0.0159)\end{array}$ & 1.1371 & & \\
\hline January & & & $\begin{array}{l}-0.7720^{\mathrm{a}} \\
(0.2433)\end{array}$ & 0.4621 & & \\
\hline February & & & $\begin{array}{l}-0.5077^{a} \\
(0.1286)\end{array}$ & 0.6019 & & \\
\hline March & & & $\begin{array}{l}-0.2703^{\mathrm{a}} \\
(0.0552)\end{array}$ & 0.7631 & & \\
\hline April & & & $\begin{array}{l}-0.1440^{\mathrm{a}} \\
(0.0286)\end{array}$ & 0.8659 & & \\
\hline May & & & $\begin{array}{c}-0.0580 \mathrm{~b} \\
(0.0254)\end{array}$ & 0.9437 & & \\
\hline June & & & $\begin{array}{l}-0.0304^{\mathrm{a}} \\
(0.0170)\end{array}$ & 0.9701 & & \\
\hline July & & & $\begin{array}{l}0.0468^{\mathrm{a}} \\
(0.0114)\end{array}$ & 1.0479 & & \\
\hline September & & & $\begin{array}{l}-0.0575^{a} \\
(0.0109)\end{array}$ & 0.9441 & & \\
\hline October & & & $\begin{array}{l}-0.0801^{\mathrm{a}} \\
(0.0097)\end{array}$ & 0.9230 & & \\
\hline November & & & $\begin{array}{l}-0.1390^{\mathrm{a}} \\
(0.0223)\end{array}$ & 0.8702 & & \\
\hline December & & & $\begin{array}{l}-0.0871^{\mathrm{a}} \\
(0.0151)\end{array}$ & 0.9166 & & \\
\hline Party size & & & & & $\begin{array}{c}0.0832^{b} \\
(0.0336) \\
-0.1280\end{array}$ & 1.0867 \\
\hline OTAs hotel & & & & & $\begin{array}{c}(0.1058) \\
0.8381^{\mathrm{a}}\end{array}$ & \\
\hline OTAs holiday home & & & & & $\begin{array}{c}(0.1722) \\
0.0682\end{array}$ & 2.3120 \\
\hline $\begin{array}{l}\text { DMO website hotel } \\
\text { DMO website }\end{array}$ & & & & & $\begin{array}{c}(0.1132) \\
0.5589^{\mathrm{a}}\end{array}$ & 1.0706 \\
\hline Holiday home & & & & & $(0.1341)$ & 1.7488 \\
\hline DMO call center & & & & & $0.4814^{\mathrm{a}}$ & \\
\hline Hotel & & & & & $(0.1518)$ & 1.6183 \\
\hline DMO call center & & & & & $0.7416^{a}$ & \\
\hline Holiday home & & & & & $(0.1449)$ & 2.0994 \\
\hline Constant & $\begin{array}{l}4.1587^{\mathrm{a}} \\
(0.1565)\end{array}$ & & $\begin{array}{l}3.2693^{\mathrm{a}} \\
(0.0776)\end{array}$ & & $\begin{array}{l}3.2930^{\mathrm{a}} \\
(0.1205)\end{array}$ & 1.0867 \\
\hline$\alpha$ & $\begin{array}{c}0.6406^{\mathrm{a}} \\
(0.0243)\end{array}$ & & $\begin{array}{c}0.4951^{\mathrm{a}} \\
(0.0250)\end{array}$ & & $\begin{array}{r}0.5888^{\mathrm{a}} \\
(0.0246)\end{array}$ & 0.8799 \\
\hline LR statistic & $142276^{a}$ & & $142762^{\mathrm{a}}$ & & $142451^{\mathrm{a}}$ & \\
\hline Akaike IC & $\begin{array}{l}9.0147 \\
a=p<0\end{array}$ & ; b $=p<0.05$ & 8.8447 & & 8.9543 & \\
\hline
\end{tabular}


Graph 1. Effect of prices on percentage variation of days of advanced booking

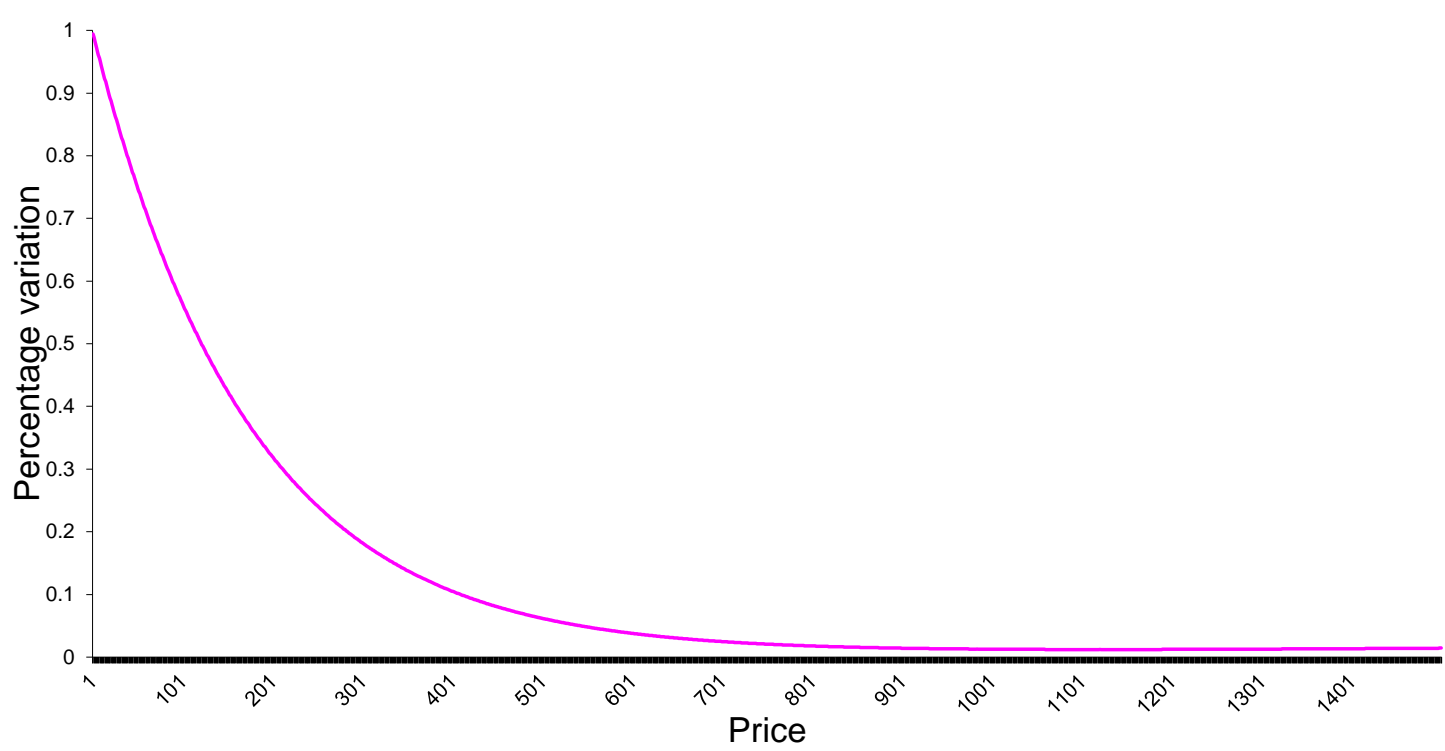

